\title{
Shehata's solution for the ex vivo lung preservation; it sounds very good
}

\author{
Mohamed SA Mohamed* \\ Department Thoracic Transplantation, University of Cologne, Germanyt
}

\begin{abstract}
The importance of lung transplantation is increasing, being the practical solution for the end stage pulmonary failure. Ex vivo graft preservation is an essential step in the transplantation surgery that consists of hypothermic preservation and normothermic perfusion.

There are many preservation solutions that are used for the ex vivo lung preservation and are commercially available or institutionally used. Based on the clinical results, the effective preservation determines the clinical outcome of the transplantation surgery.

Despite the great progress in the development of the preservation solutions, there is a continuous interest and need for further development, in order to achieve the perfectionism of the technique. This paper is an opinion article that theoretically introduces a new preservation solution, which has the potential to counteract the hazards facing the graft ex vivo and after transplantation, based on the most recently published data.
\end{abstract}

\section{Mini review}

The biological challenges facing the lung graft or the solid organ grafts in general are mainly the ischemic reperfusion injury (IRI) and the host-graft interaction after transplantation. Both challenges are of inflammatory nature, which involves tissue and functional injuries that lead to the release of the inflammatory cytokines and the recruitment of the inflammatory cells. A recent study published by Andreasson et al. crowns the research achieved in this regards through stating the increased production of interleukin (IL) $1 \beta$ in the lung graft vasculature during ex vivo perfusion to be responsible for the increased ICAM-1 expression on the endothelial cells, and the enhanced endothelialneutrophilic adhesion. In addition, they experimentally report IL1 $\beta$ to be the main marker capable of distinguishing between successful and non-successful grafts, where the perfusate levels of the IL1 $\beta$ measured 30 minutes after perfusion could discriminate the in-hospital mortality and the 1year patient's survival with a sensitivity and specificity of $100 \%$ [1].

While the exact effects of the inflammatory cytokines, especially IL1 $\beta$, on the mechanical and functional capabilities of the lung graft (correspondingly the functional capabilities of other solid organ grafts) could be further studied, together with the possibly involved molecular pathophysiological pathways, it is well known that the rise of the inflammatory cytokines is linked to multi-organ dysfunction, up to multi-organ failure in cases of cytokine storm [2]. Nevertheless, it is logic that the increased cytokine production within a graft reflects the degree of the tissue damage, hence, the impaired organ functions. However, the manifestations of the IRI and the post-transplant hostgraft interaction rely not only on the autocrine and paracrine signaling of the inflammatory cytokines, but also, and to a great extent, on their chemotactic and recruiting role of the circulating leukocytes that migrate into the newly transplanted graft initiating various forms of the destructive inflammatory reactions associated with the various forms of acute and chronic graft dysfunctions [3].
Some studies confirmed a significant correlation between IL6 and the 30-day mortality after transplantation. Similarly, IL8 correlates with the incidence of the primary graft dysfunction $[1,4]$. However, the study by Andreasson et al. reported IL1 $\beta$ to be the most indicative effector responsible for the endothelial activation and the increased leucocytic adhesion, and to be the most effective marker capable of differentiating between the in-hospital post-transplant survival and mortality, with a sensitivity and specificity up to $100 \%$ [1].

The cytokine production in response to the IRI may follow the following sequence of events: [5]

- IRI $\rightarrow$ the activation of toll-like receptors (TLRs), the increased production of reactive oxygen species (ROS), and the inhibition of $\mathrm{Na}+/ \mathrm{K}+$ ATPase and other $\mathrm{K}+$ channels $\rightarrow$ the priming and activation of the graft inflammasomes $\rightarrow$ the increased production and release of IL1 $\beta$ and IL18, which increase the induction of IL6.

- In response to tissue damage and IRI, the production of tumor necrosis factor (TNF) $\alpha$ increases $\rightarrow$ IL1 $\beta$ and TNF $\alpha$ upregulate the TLR2 on the surfaces of the endothelial cells $\rightarrow$ versican, which is concomitantly induced by the activated TLR4, interacts with TLR2 $\rightarrow$ increased production of IL8 $\rightarrow$ the activation of the vascular endothelium and the increase of the leucocytic adhesion and migration into the graft.

Correspondence to: Mohamed S. A. Mohamed, Department Thoracic Transplantation, University of Cologne, Deutz-Kalker Str. 118, 50679, Cologne, Germany, Tel: +491625706493; E-mail: mohammed.shehatta1@ gmail.com

Key words: ex vivo lung perfusion, lung graft preservation, lung transplant, preservation solution

Received: November 15, 2017; Accepted: December 18, 2017; Published: December 22, 2017 
Based on this understanding, the following interventions seem to have a very significant potential: [6]

- The antagonization of the increased ROS production during ex vivo graft preservation through the inclusion of potent antioxidants.

- The interference with the increased ROS production and activated graft inflammasomes through the activation of the inhibited $\mathrm{K}+$ channels $\rightarrow$ the attenuation of IL1ß, IL18 and IL6 production.

- The antagonization of TNF $\alpha \rightarrow$ the interference with IL8 production.

- Collectively, the interference with the endothelial cells activation and the recruitment and migration of the circulating leukocytes into the graft following transplantation. In addition to the attenuation of the cytokine overproduction, limiting their hazardous autocrine, paracrine, and remote signaling.

There are many preservation solutions that are available either in the market or for the institutional use. Euro-Collins (EC) solution was initially the solution of choice until it was replaced in 1988 by the University of Wisconsin (UW) solution [7], whose high viscosity has been involved in organ dysfunction, which motivated the development of other solutions including Celsior (CEL) and histidine tryptophan ketoglutarate (HTK) [8].

Due to its unique metabolic requirements and the unique physiology, special solutions, such as Perfadex (PER), are particularly designed for the lung. All solutions consist of several composite elements, which have some advantages and disadvantages (Table 1).

Previously, high $\mathrm{K}+$ preservation solutions were used and were associated with pulmonary vascular spasms and increased production of ROS. Low potassium (dextran) solutions are currently widespread and are associated with better clinical outcomes.

Although 2 studies have confirmed Celsior's ability to provide similar clinical results to those of the Perfadex solution, with additional trends towards better survival and less incidence of chronic lung allograft dysfunction, especially with longer ischemic periods, Perfadex remains the most widely used preservation solution in most lung transplant centers $[9,10]$.

In addition to the hypothermic preservation solutions, there are other solutions that are specifically used for the normothermic ex vivo graft perfusion, mostly Organ Care System and Steen solutions. The later is a colloidal solution that resembles the extracellular fluid (low $\mathrm{K}+$ ), and contains albumin and dextran 40 to provide colloidal activity and endothelial protection [11].
According to the current surgical practice, the reported results, using various preservation solutions are promising, with the ability of EVLP to convert the non-acceptable grafts into acceptable in rates between $87-97 \%$ based on the graft recruitment protocol, where the more aggressive is the strategy, the lower is the conversion rate (12).

To increase the quality of the ex vivo graft preservation, and to provide the ability for more aggressive graft recruitment, through the application of the above discussed interventions, the Shehata's solution has been introduced (Table 2).

This solution aims to provide better conditioning of the lung grafts that have extended criteria, in order to increase the available donor pool. The levels of various electrolytes in the solution are based to resemble the physiological serum levels. Sucrose is added to provide colloidal force and stabilization of the cellular membranes [13]. Human serum albumin is included to provide oncotic pressure that helps the resolution of the pulmonary edema. Glucose adds to the actions of sucrose and albumin, in addition to providing nutrition.

Glutathione and vitamin $\mathrm{C}$ provide potent antioxidant function, antagonizing ROS [14,15]. Vitamin C and Pinacidil activate the ATPsensitive $\mathrm{K}+$ channels. In addition, infliximab antagonizes TNFa. All together have the potential to significantly oppose and attenuate the IRI $[5,6,15]$.

Nevertheless, the $\mathrm{Na}+/ \mathrm{K}+$ ATPase is inhibited by hypoxia and cold preservation, and the absence of the shear stress during ischemia is associated with impaired functions of various $\mathrm{K}+$ channels, cell membrane depolarization, increased activity of nicotinamide-adeninedinucleotide phosphate oxidase and xanthine oxidase enzymes, and impaired mitochondrial activity, leading to the increased production of ROS that activate protein kinase $\mathrm{C}-\zeta$, starting a sequence of phosphorylationubiquitination-recognition-endocytosis-degradation of $\mathrm{Na}+\mathrm{K}+$ ATPase. Insulin interferes with that sequence of events through the activation and recruitment of $\mathrm{Na}+\mathrm{K}+$ ATPase, the induction of $\mathrm{Na}+/ \mathrm{K}+$ ATPase, and the inhibition of $\mathrm{K}+$ efflux channels. As $\mathrm{Na}+\mathrm{K}+$ ATPase is also essential for the synchronized action of $\mathrm{Na}+$ transport, insulin supplementation during cold static graft preservation, as well as during ex vivo perfusion, could be useful for glucose utilization, ATP production, $\mathrm{Na}+\mathrm{K}+$ ATPase activation, inhibition of $\mathrm{K}+$ efflux, and clearance of alveolar edema [16]. Preclinical and clinical studies should be conducted to test the efficacy and applicability of these theoretical notions.

\section{Conflicts of interest}

All the intellectual properties included in this manuscript, or any of the referred publications of the author, belong solely to the author.

Table 1. Characteristics of some lung preservation solutions.

\begin{tabular}{|c|c|c|c|c|c|}
\hline Solution & EC & UW & CEL & HTK & PER \\
\hline Colloid Component & Glucose & LactoB, raffinose, HES & LactoB, mannitol & Mannitol & Dextran \\
\hline Puffer & Phos, bicarb & Phos & Histidine & Histidine & Phos \\
\hline Antioxidans & & AlloP, GSH & GSH, mannitol & Trp, mannitol & \\
\hline Osmolarity $(\mathrm{mOsm} / \mathrm{L})$ & 375 & 330 & 320 & 310 & 292 \\
\hline Glucose & 180 & & & & 5 \\
\hline $\mathrm{Na}+$ & 10 & 25 & 100 & 15 & 138 \\
\hline $\mathrm{K}+$ & 115 & 120 & 15 & 10 & 6 \\
\hline $\mathrm{Ca} 2+$ & & & 0.25 & 0.02 & \\
\hline $\mathrm{Mg} 2+$ & & 5 & 13 & 4 & 0.8 \\
\hline $\mathrm{Cl}-$ & 15 & 20 & & 32 & 142 \\
\hline \multicolumn{2}{|c|}{ Other Components } & & & $\alpha-K G$ & SO42- 0.8 Dextran $40 \mathrm{~g} / \mathrm{L}$ \\
\hline
\end{tabular}

All units are in mmol/L, unless otherwise stated. Abbreviations: EC: Euro Collins; UW: University of Wisconsin; HTK: histidine-tryptophan ketoglutarates; CEL: Celsior; PER:

Perfadex; LactoB: lactobionate; HES: hydroxyethyl starch; Phos: phosphates; Bicarb: bicarbonates; GSH: glutathione; Trp: tryptophan; A-KG: ketoglutarates. 
Table 2. Characteristics of Shehata's lung preservation solution. The solution is to be supplemented with $500 \mathrm{mg}$ methylprednisolone, $500 \mathrm{mg}$ imipenem/cilastatin and $3000 \mathrm{IU}$ heparin, and to be used for both graft perfusion and static preservation.

\begin{tabular}{|c|c|}
\hline Ingredient & Recommended Dose \\
\hline Sucrose & $0.5 \mathrm{M}$ \\
\hline Sodium & $135-145 \mathrm{mmol} / \mathrm{L}$ \\
\hline Glucose & $100-120 \mathrm{mg} / \mathrm{dL}$ \\
\hline Potassium & 3.5 to $5.5 \mathrm{mEq} / \mathrm{L}$ \\
\hline Phosphate & $1.0 \mathrm{mmol} / 1$ \\
\hline Calcium & $2.2 \mathrm{mmol} / 1$ \\
\hline Magnesium & $1.7-2.2 \mathrm{mg} / \mathrm{dL}$ \\
\hline Human serum albumin & $50 \mathrm{~g} / \mathrm{L}$ \\
\hline Carbonate & $29 \mathrm{mmol} / \mathrm{L}$ \\
\hline Chloride & $100 \mathrm{mEq}$ \\
\hline Vitamin C & $0.5 \mathrm{~g} / \mathrm{L}$ \\
\hline Glutathion & $1500 \mathrm{mg} / \mathrm{L}$ \\
\hline Insulin & $200 \mathrm{pmol} / \mathrm{L}$ \\
\hline Pinacidil & $0.25-0.3 \mathrm{mg} / \mathrm{L}$ \\
\hline Infliximab & $3-5 \mathrm{mg} / \mathrm{L}$ \\
\hline Distilled water & Dissolvent \\
\hline pH & 7.4 \\
\hline
\end{tabular}

All rights are reserved exclusively for the author (patent protected). Reproduction or use of any of these intellectual properties, either directly or indirectly, requires the written permission of the author. The author welcomes and appreciates cooperation for experimental and clinical studies. No funding was provided to develop this work.

\section{References}

1. Andreasson ASI, Borthwick LA, Gillespie C, Jiwa K, Scott J, et al. (2017) The role of interleukin- $1 \beta$ as a predictive biomarker and potential therapeutic target during clinical ex vivo lung perfusion. J Heart Lung Transplant 36: 985-995. [Crossref]

2. Tisoncik JR, Korth MJ, Simmons CP, Farrar J, Martin TR, et al. (2012) Into the eye of the cytokine storm. Microbiol Mol Biol Rev 76: 16-32. [Crossref]
3. Verleden GM, Raghu G, Meyer KC, Glanville AR, Corris P (2014) A new classification system for chronic lung allograft dysfunction. J Heart Lung Transplant 33: 127-133. [Crossref]

4. Saito T, Takahashi H, Kaneda H, Binnie M, Azad S, et al. (2013) Impact of cytokine expression in the pre-implanted donor lung on the development of chronic lung allograft dysfunction subtypes. Am J Transplant 13: 3192-3201. [Crossref]

5. Mohamed MS (2015) Could Ex Vivo Lung Perfusion Be a Platform to Decrease the Incidence of Chronic Lung Allograft Dysfunction? Arch Med Res 46: 240-243. [Crossref]

6. Mohamed MS (2015) Translational Insights on Lung Transplantation: Learning from Immunology. Iran J Immunol 12: 156-165. [Crossref]

7. Mühlbacher F, Langer F, Mittermayer C (1999) Preservation solutions for transplantation. Transplant Proc 31: 2069-2070. [Crossref]

8. Feng XN, Xu X, and Zheng SS (2006) Current status and perspective of liver preservation solutions. Hepatobiliary Pancreat Dis Int 5: 490-494. [Crossref]

9. Menezes AQ, Pego-Fernandes PM, Cardoso PF (2012) Comparison of Celsior and Perfadex lung preservation solutions in rat lungs subjected to 6 and 12 hours of ischemia using an ex-vivo lung perfusion system. Clinics (Sao Paulo) 67: 1309-1314. [Crossref]

10. Gohrbandt B, Simon AR, Warnecke G (2015) Lung preservation with Perfadex or Celsior in clinical transplantation: A Retrospective Single-Center Analysis of Outcomes. Transplantation 99: 1933-1939. [Crossref]

11. Van Raemdonck D, Neyrinck A, Cypel M, et al. (2015) Ex-vivo lung perfusion. Transpl Int 28: 643-656. [Crossref]

12. Sage E, Mussot S, Trebbia G, Puyo P, Stern M, et al. (2014) Lung transplantation from initially rejected donors after ex vivo lung reconditioning: the French experience. Eur J Cardiothorac Surg 46: 794-799. [Crossref]

13. Ali Mohamed MS (2015) Slow cryopreservation is not superior to vitrification in human spermatozoa; an experimental controlled study. Iran J Reprod Med 13: 633644. [Crossref]

14. Mohamed S. A. Mohamed (2014) Antagonizing reactive oxygen species during ex vivo lung perfusion. Am J Physiol Lung Cell Mol Physiol 307: L908. [Crossref]

15. Mohamed MS (2016) Ascorbic Acid Supplementation During Ex Vivo Lung Perfusion. Exp Clin Transplant 14: 112-113. [Crossref]

16. Mohamed MS (2016) Insulin Supplementation of the Lung Graft Cold Preservation Solution. Ann Thorac Surg 101: 411-412. [Crossref]

Copyright: (C2017 Mohamed MSA. This is an open-access article distributed under the terms of the Creative Commons Attribution License, which permits unrestricted use, distribution, and reproduction in any medium, provided the original author and source are credited. 